\title{
Hypofractionated Gamma Knife Stereotactic Radiosurgery as a Tool for Intracranial Mesenchymal Chondrosarcoma Local Treatment: Case Report and Literature Review
}

\author{
Domantas Jakstas ${ }^{1}$, Sarunas Tamasauskas ${ }^{2}$, Andrius Radziunas ${ }^{2 *}$ and Arimantas Tamasauskas ${ }^{3}$ \\ ${ }^{1}$ Medical Academy, Lithuanian University of Health Sciences, Lithuania \\ ${ }^{2}$ Department of Neurosurgery, Medical Academy, Lithuanian University of Health Sciences, Lithuania \\ ${ }^{3}$ Neuroscience institute of Lithuanian University of Health Sciences, Lithuania
}

*Corresponding author: Andrius Radziunas, Department of Neurosurgery, The Hospital of Lithuanian University of Health Sciences

Kauno klinikos, Eiveniu st. 4, Kaunas LT-50161, Lithuania

ARTICLE INFO
Received: 㓞 April 26, 2021
Published: 幽 May 06, 2021

Citation: Domantas J, Sarunas T, Andrius R, Arimantas T. Hypofractionated Gamma Knife Stereotactic Radiosurgery as a Tool for Intracranial Mesenchymal Chondrosarcoma Local Treatment: Case Report and Literature Review. Biomed J Sci \& Tech Res 35(4)-2021. BJSTR. MS.ID.005729.

Keywords: Extraosseous mesenchymal chondrosarcoma; Hypofractionated Gamma knife; Craniospinal irradiation

\section{ABSTRACT}

Background: Mesenchymal chondrosarcoma is a rare, aggressive cartilaginous forming tumor rarely encountered in neurosurgical practice. Due to low incidence and lack of study of this disease, treatment options remain controversial, and due to its aggressive nature and high probability of metastasis, prognosis remains poor.

Case Description: A 3.5-year-old male patient diagnosed with extraosseous mesenchymal chondrosarcoma, which was first located in the lumbar spine, treatment started with subtotal tumor resection, local radiotherapy, and chemotherapy. PET and MRI did not show metastasis or recurrent tumors for 1.5 years. Then tumor metastasized infratentorialy. This lesion was treated with surgery and chemotherapy. However, the recurrence was detected a few months later in the region of the cerebellum. The patient underwent subtotal tumor removal. Due to the patient's young age, big treatment volume, and tumor remnant proximity to the brain stem, hypofractionated stereotactic radiosurgery was chosen. Leksell Gamma Knife Icon was used to deliver 5 stereotactic radiosurgery fractions. Local control was achieved for 9 months. Later MRI showed progression and new metastasis along the spinal canal. To our knowledge, it is the first publication presenting hypofractionated stereotactic radiosurgery with Gamma knife after extraskeletal mesenchymal chondrosarcoma neurosurgical resection.

Conclusion: Surgical resection should be the cornerstone for treating this disease, followed by adjuvant treatment modalities - radiotherapy and chemotherapy. Hypofractionated radiosurgery with the Gamma knife can achieve local control near critical brain structures. However, due to high metastatic potential, conventional craniospinal irradiation should be considered as the first line treatment option after the first tumor recurrence.

\section{Introduction}

Mesenchymal chondrosarcomais a rare, aggressive cartilaginous forming tumor that is rarely encountered in neurosurgical practice. Due to low incidence and lack of study of this disease, treatment options remain controversial, and due to its aggressive nature and high probability of metastasis, prognosis remains poor. In this article, we present a case of mesenchymal chondrosarcoma, treated with Gamma knife hypofractionated radiosurgery in combination with surgical resection, radiation therapy, and chemotherapy. We also present a review of English literature regarding this topic. 


\section{Case Report}

\section{History and Physical Examination}

A 5-year-old male patient was admitted to the neurosurgery department, complaining of slight gait instability and weakness on the body's right side. The patient was previously treated in another institution for extraosseous mesenchymal chondrosarcoma, which was first located in the L3-L4 segments of the lumbar spine. Treatment included subtotal tumor resection, local radiotherapy, and chemotherapy. PET and MRI did not show metastasis or recurrent tumors for 1.5 years. Later, the tumor metastasized infratentorialy to the region of the right cerebellar hemisphere and right inferior cerebellar peduncle. This lesion was treated with a combined method of surgery and chemotherapy. However, the pathological process was detected a few months later in the region of the cerebellum.

Upon admission to our department, the patient was alert, well orientated with normal physical findings. Neurological examination found that the patient exhibited gait disturbances and a slight instability and a medial deviation of the left foot while walking, and weakness on the body's right side. No other pathological findings were found upon initial neurological examination. Magnetic resonance imaging demonstrated a new large lesion in the right cerebellar hemisphere, measuring 25×16×27mm, and increased the previously managed lesion around the brainstem, measuring 13x19x11mm. After the introduction of Gadolinium-based contrast material, both lesions were contrast-enhanced with minimal perifocal edema (Figure 1).

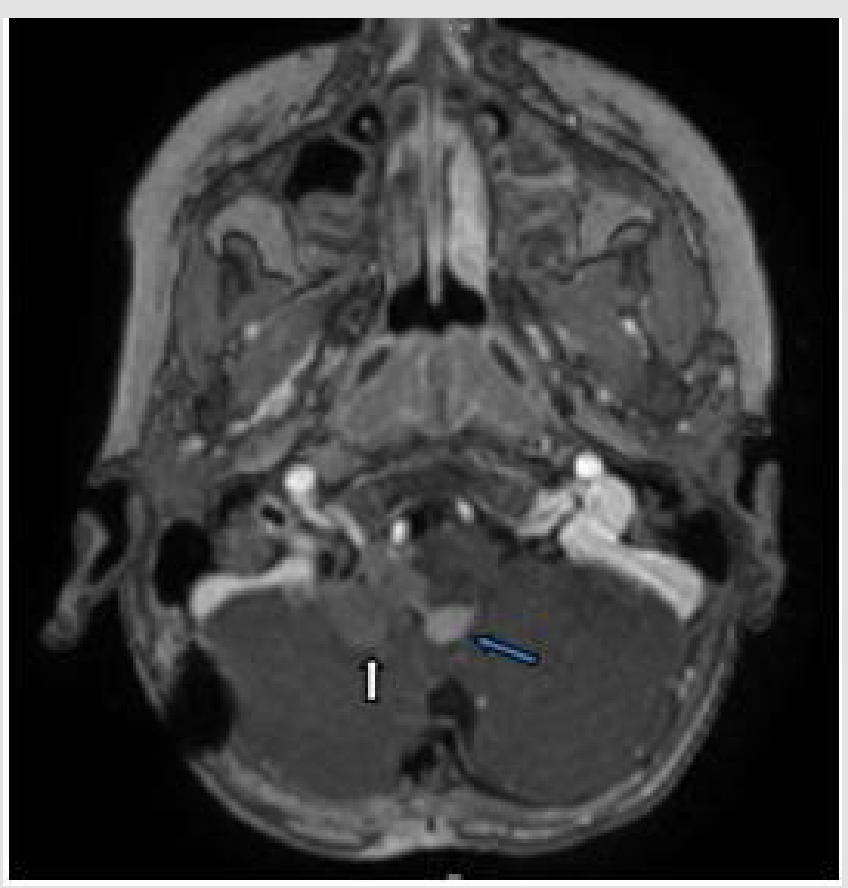

Figure 1: Brain MRI 3 months after first tumor resection. New metastasis in the right cerebellar hemisphere (white arrow), and progression of the previously resected tumor (blue arrow).

A decision was made to attempt a maximum safe resection of the lesions and afterward, administer adjuvant radiosurgical treatment employing Gamma Knife for the tumor and postoperative fossa remnants. The patient underwent tumor removal via suboccipital medial osteoplastic craniotomy in the posterior fossa. The tumor was excised within the visible margins from the dorsal side of the cerebrospinal portion of the medulla oblongata, the left premedullary cistern that it had invaded right premedullary cistern and right cerebellar hemisphere, as well as from other critical neurovascular structures. After the resection patient exhibited a mild right hemiparesis with no cranial nerve deficits.
Microscopic examination of the tumor specimen revealed spindle-shaped atypical cells, with polymorphic oval nuclei and frequent mitosis. The immunohistochemical examination demonstrated that the neoplastic cells react heavily with vimentin CD99 and INI-1, GFAP, and some cells demonstrated positivity with S-100 and SOX-10, which is consistent with the diagnosis of mesenchymal chondrosarcoma. The aggressive nature of this tumor can be illustrated by the fact that the MRI used for planning the Gamma knife procedure revealed visible growth of the neoplasm near the resection cavity and progression down the spinal canal in just 10 days after postoperative MRI (Figure 2). 

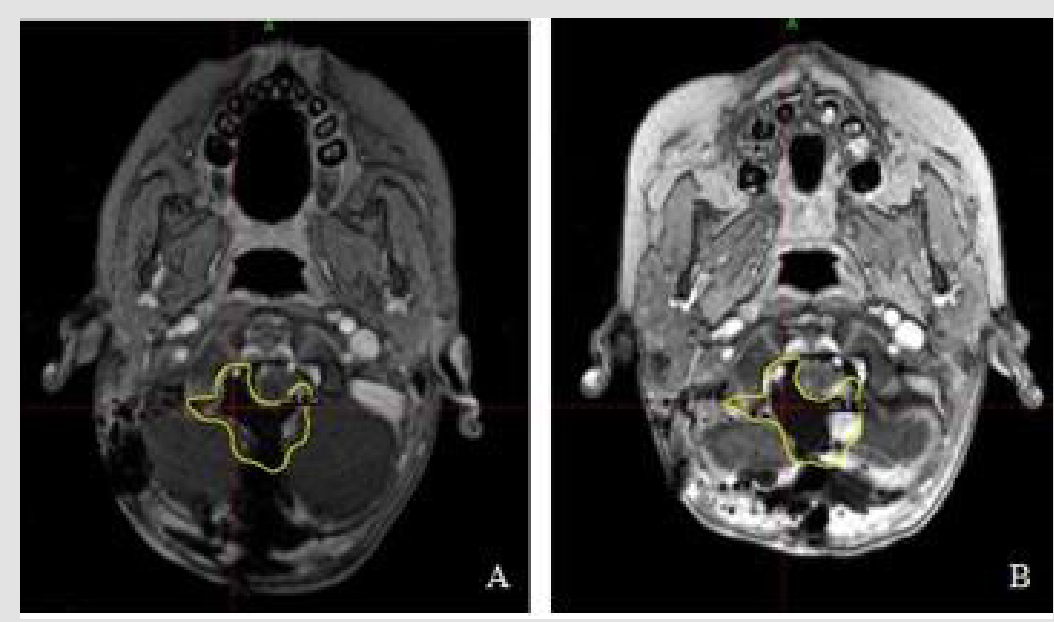

Figure 2: A) Brain MRI after the second surgery. B) Brain MRI 10 days later after tumor removal. Growth of the neoplasm near the resection cavity. Yellow line marks 55\% isodose.

\section{Radiosurgery and Outcomes}

Due to the patient's young age, big treatment volume, and tumor proximity to the brain stem, hypofractionated stereotactic radiosurgery was chosen. Leksell Gamma Knife Icon ${ }^{\circledR}$ (Elekta Instruments, $\mathrm{AB}$, Sweden) was used to deliver 5 stereotactic radiosurgery fractions to the neoplasm remnants, the tumor bed itself, and the tumor progression area.

Due to the young age, the patient was in general anesthesia during MRI scanning and every radiosurgical session. A thermoplastic mask was formed and used combined with a rigid cervical collar to stabilize and replicate head and neck position during every fraction. CBCT and patient repositioning were made to maximize the cervical part match and minimize the probability of spinal cord movement in the stereotactical treatment field. Five fractions marginal dose was $22.5 \mathrm{~Gy}$ at the $55 \%$ prescription isodose. The target volume was $14.86 \mathrm{~cm}^{3}$, and the prescription isodose volume was $16.86 \mathrm{~cm} 3$. The coverage, the selectivity, the Paddick, and the gradient index were 0.96, 0.56, 0.858, and 2.95, respectively. 171 isocenters were used, including composite shots. The $0.1 \mathrm{~cm}^{3}$ of brain stem received $23.8 \mathrm{~Gy}$.

After 2 months patient showed an improvement of rightside hemiparesis. MRI examination revealed that the previously found contrast-enhancing lesions in the posterior fossa were no longer detectable, linear enhancement around the brain stem was decreased (Figure 3). However, there were multiple spinal intradural lesions. Therefore, the patient underwent additional chemotherapy and radiotherapy. 9 months after treatment, MRI examinations showed progression and new metastasis along the spinal canal: the cervical spine and thoracolumbar segments. However, no new metastasis or progression was detected in the area treated with hypofractionated stereotactic radiosurgery.

\section{Discussion}

Mesenchymal chondrosarcoma is a sporadic, highly aggressive malignant tumor, accounting for $13.3 \%$ to $16.2 \%$ of all chondrosarcomas and $0,16 \%$ of all intracranial tumors [1,2]. Dahlin and Henderson first described it in 1962 [3]. These neoplasms are usually found in the craniospinal meninges [4], usually affecting patients in their second or third decade of life, more frequently occurring in females [5]. Although the exact pathogenesis of this tumor remains unknown, due to its intimate relationship with the meninges, the dura matter is considered to be the site of origin of this neoplasm [6], with some theories proposing that the potential sources might be the embryonal cartilage in both the fibroblasts and the dura, meningeal fibroblasts, and the dural multipotent mesenchymal cells $[7,8]$. 

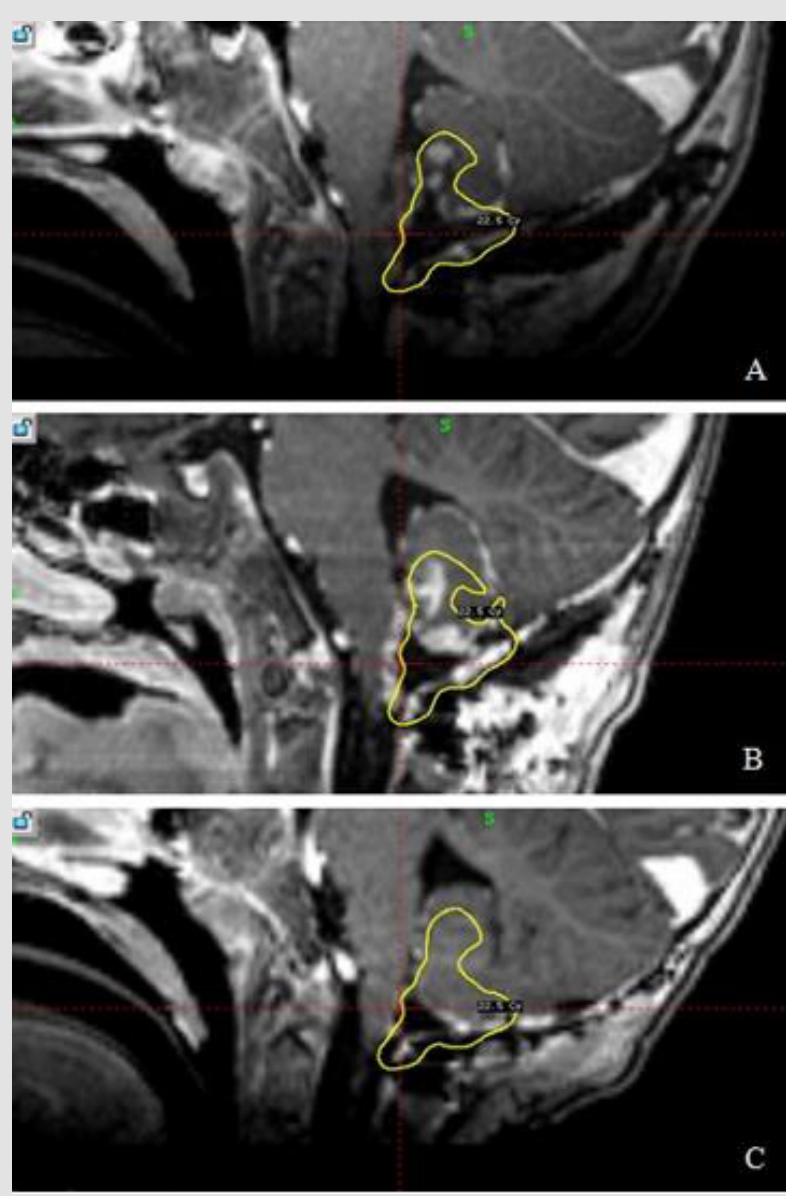

Figure 3: A) Postoperative MRI. B) MRI before stereotactic radiosurgery. C) MRI 2 months after the second surgery. Previously found contrast-enhancing lesions in the posterior fossa were no longer detectable, linear enhancement around the brain stem decreased. Yellow line marks 55\% isodose.

Histologically, mesenchymal chondrosarcoma is characterized by a bimorphic pattern consisting of small, round, undifferentiated cells and spaces of mature, well-formed hyaline cartilage [9]. At the same time, upon macroscopic examination, this tumor is often seen smooth, firm on palpation masses of various colors, ranging from grey to red [10]. Mesenchymal chondrosarcoma can also be diagnosed by performing immunohistochemical analysis. Using this method, the tumor's mesenchymal components are positive for CD99, vimentin, and Leu7, while the cartilaginous portion is positive for S100 [11]. Clinically these tumors present with symptoms caused by increased intracranial pressure or the compression of adjacent neurological structures. Frequent symptoms include a progressive history of headache, third cranial nerve palsy, and decreased vision [12]. Due to the low incidence, the mesenchymal chondrosarcoma is often studied together with the classical chondrosarcoma. However, these tumors have numerous clinical differences. In their retrospective analysis of 74 patients (13 MSC, 61 CCS), Ma and colleagues found that the mesenchymal type was associated with a younger age of the patient, higher tumor volume. They also found that the mesenchymal variant was less often located at the skull base [13].
Besides, the mesenchymal chondrosarcoma is often associated with poor prognosis compared to the classical variant. In their systematic review of 560 patients, Bloch and colleagues found that patients who had the mesenchymal chondrosarcoma exhibited a high recurrence rate $(63 \%$ vs. $16 \%$ after a median follow up at 60 months) when compared with the classical variant (2). Similarly, Ma et al. [13] report a significantly shorter progressionfree survival after 5 years (49\% for MSC vs. 67,3\% for CCS) [13]. This tumor also has a high metastatic potential, with the most frequent areas of spreading being the lumbar vertebrae, heart, ribs, and various intraabdominal structures [14]. The cornerstone for treating both classical and mesenchymal chondrosarcoma should be maximum safe tumor resection to obtain biopsy material and achieve cytoreduction.

However, a gross total resection is often difficult to achieve because of the tumor's proximity to the nearby critical neurovascular structures [15]. Radical surgery can be associated with increased morbidity. Sekhar et al. have reported 22 cases of chondrosarcoma patients who underwent radical resection. $41 \%$ of these patients have developed new cranial neuropathies after 
surgery [16]. Similarly, Samii et al. [17] reported that after surgical resection, 25\% had new cranial nerve deficits [17]. Therefore, some authors argue that maximum safe tumor resection and adjuvant radiotherapy for the tumor remnants is the preferred approach for both classical and mesenchymal chondrosarcoma [18]. Some authors suggest adjuvant radiotherapy even after radical resection was achieved due to the aggressive nature of mesenchymal chondrosarcoma [19]. Although there are no studies published on this topic exclusively, and the vast majority of information is from case reports, stereotactic radiosurgery with Gamma knife is a feasible management option for mesenchymal chondrosarcoma local control.

However, due to the rarity of mesenchymal chondrosarcoma, there have been no studies that tried to evaluate the effectiveness of GKS while treating mesenchymal chondrosarcoma, although some authors have reported the use of gamma knife surgery for this neoplasm with optimistic results (Table 1). Xiao et al. [20] and Wakabayashi et al. [21] both reports using Gamma Knife radiosurgery, with good local control and no recurrence after 6-30 months. Förander et al. [22] reports a good local control in the site of surgical resection after treatment with GKS, however the authors report out of field growth after 26 months follow up. On the contrary Inenaga et al. [4] reports local growth of the tumor in the treated site, after 6 months. This complex disease is treated with other adjuvant treatment modalities, such as Linac radiosurgery, proton beam therapy and conventional radiotherapy (Table 2). Most of the information regarding other adjuvant modalities for treating mesenchymal chondrosarcoma comes from case reports. Yassa et al. [23] and Anvari et al. [24] both report the use of conventional radiotherapy in the resection cavity with no recurrence after $12-60$ months.

Table 1: Characteristics in published studies and case reports of mesenchymal chondrosarcoma treated with GKS.

\begin{tabular}{|c|c|c|c|c|c|}
\hline Reference & $\begin{array}{c}\text { Patient's age and } \\
\text { sex }\end{array}$ & Tumor site & Tumor size & Marginal dose & Fesult \\
\hline Xiao et al. [21] & 23 y.o, $\mathrm{M}$ & Posterior fossa & $5.7 \times 4.7 \times 5.2 \mathrm{~cm}$ & N/A & N/A \\
\hline $\begin{array}{c}\text { Wakabayashi et al. } \\
{[22]}\end{array}$ & 22 y.o, F & Lateral ventricle & N/A & No recurrence \\
\hline Inenaga et al. [4] & 21 y.o. M & Sellar region & N/A & 30 Gy 50\% isodose & Local recurrence \\
\hline Förander et al. [20] & 36 y.o, F & Falx & $4.6 \mathrm{~cm} 3$ & $\begin{array}{c}\text { Fractionated EBRT } \\
\text { to the tumor area. } \\
\text { SRS } 18 \text { Gy } 48 \% \\
\text { isodose }\end{array}$ \\
\hline
\end{tabular}

N/A - not available, F/U - followup, Mths- months, M- male, F- female.

Table 2: Characteristics in published case reports of mesenchymal chondrosarcoma being treated with radiation modalities.

\begin{tabular}{|c|c|c|c|c|c|c|c|}
\hline Reference & $\begin{array}{l}\text { Patient's age } \\
\text { and sex }\end{array}$ & Tumor site & $\begin{array}{l}\text { Tumor size } \\
\text { (cm) }\end{array}$ & Dosage and modality & Rt site & F/O & Result \\
\hline Lin et al. [24] & 21 y.o, female & Right tentorium & $2,8 \times 2 \times 2,7$ & $\begin{array}{l}\text { Conventional RT. } 36 \text { Gy } \\
-20 \text { fractions }\end{array}$ & Cranio-spinal & 6 mths & No recurrence \\
\hline $\begin{array}{l}\text { Shabani et al. } \\
\text { [25] }\end{array}$ & 23 у.о, F & Right parietal & $6,7 \times 4,4 \times 5,7$ & $\begin{array}{l}\text { Proton beam therapy. } \\
\qquad 70 \mathrm{~Gy}\end{array}$ & Resection cavity & 35 mths & Died of disease \\
\hline Yassa et al. [26] & 44 y.o, M & $\begin{array}{c}\text { Right } \\
\text { cerebellum }\end{array}$ & $\mathrm{N} / \mathrm{A}$ & $\begin{array}{l}\text { Conventional RT. } 54 \text { Gy } \\
30 \text { fractions daily. }\end{array}$ & Resection cavity & 60 mths & No recurrence \\
\hline $\begin{array}{l}\text { La Spina et al. } \\
\text { [27] }\end{array}$ & 14 y.o, F & $\begin{array}{l}\text { Right posterior } \\
\text { fossa }\end{array}$ & $7 \times 6,3 \times 3,3$ & $\begin{array}{l}\text { Hyperfractionated RT: } \\
\text { a daily dose of } 3,120 \\
\text { cGy on the brain and a } \\
\text { boost of } 3,120 \text { cGy to } \\
\text { the posterior fossa. }\end{array}$ & $\begin{array}{l}\text { Whole brain and } \\
\text { a boost to post. } \\
\text { fossa. }\end{array}$ & 24 mths & No recurrence \\
\hline $\begin{array}{l}\text { Merimsky et al. } \\
{[28]}\end{array}$ & 33 у.о, F & Temporal lobe & $\mathrm{N} / \mathrm{A}$ & $\begin{array}{l}\text { Conventional RT. } 50 \text { Gy, } \\
25 \text { fractions }\end{array}$ & Resection cavity & 12 mths & Died of disease \\
\hline $\begin{array}{l}\text { Nozaki et al. } \\
\text { [29] }\end{array}$ & 15 y.o, M & Jugular foramen & $3 \times 4 \times 5$ & $\begin{array}{c}\text { Linac radiosurgery. } \\
\text { marginal -13 Gy Max } \\
\text { dose - } 26 \text { Gy, }\end{array}$ & Residual mass & 35 mths & No recurrence \\
\hline Anvari et al. [30] & 29 y.o, M & $\begin{array}{l}\text { Left } \\
\text { frontoparietal } \\
\text { region }\end{array}$ & $4 \times 3,5 \times 3,5$ & Conventional RT. 60 Gy & Resection cavity & 12 mths & No recurrence \\
\hline $\begin{array}{c}\text { Murakami et al. } \\
\text { [23] }\end{array}$ & 18 у.о, M & $\begin{array}{l}\text { Cavernous } \\
\text { sinus, anterior } \\
\text { and middle } \\
\text { skull base }\end{array}$ & $\mathrm{N} / \mathrm{A}$ & $\begin{array}{l}\text { SRS } 15 \text { Gy. Additional } \\
\text { multiple SRT and SRS } \\
\qquad(18-45 \text { Gy })\end{array}$ & $\begin{array}{l}\text { Resection cavity } \\
\text { and residual } \\
\text { tumor }\end{array}$ & 125 mths & $\begin{array}{l}30 \text { mths after initial } \\
\text { surgery and SRS - } \\
\text { recurrence } 125 \text { mths } \\
\text { - tumors controlled. }\end{array}$ \\
\hline
\end{tabular}

N/A - not available, F/U - followup, Mths- months, M- male, F- female. 
Similarly, Lin et al. [25] has reported using conventional radiotherapy in the cranio-spinal region with no tumor recurrence after 6 months. Some authors report the use of hyperfractionated radiotherapy with boost and Linac stereotactic radiosurgery with no recurrence after treatment for up to 35 months [26,27]. Despite successful use of proton therapy in treating classical chondrosarcoma [28] this treatment strategy was not successful in the case of mesenchymal chondrosarcoma and the patient died of disease. However, a sole case report cannot determine the effectiveness of proton beam therapy, therefore this question requires more research. Murakami and colleagues [29] report the case in which multiple treatments were used in treating a patient with this complex disease. After combination of multiple surgical, SRS, RT and chemotherapy sessions, tumor control was achieved after 125 months following the initial surgery. As there is still no golden standard for mesenchymal chondrosarcoma treatment it is up to multidisciplinary teams to decide the best way to treat patient after surgery according to its age, functional status, existence of metastasis and tumor site. Usage of conventional radiotherapy, proton beam therapy, stereotactic radiosurgery, or combinations of these treatments is a necessity to control recurrence and progression of this disease [30,31].

Due to the big tumor and postoperative cavity volume near critical structures, we used hypofractionated radiosurgery. We achieved good local control for 9 months, but conventional RT had to be used due to multiple metastases outside our target volume. In our opinion, hypofractionated radiosurgery with a Gamma knife can be administered as a tool just for local control of mesenchymal chondrosarcoma. However, due to high metastatic potential, conventional craniospinal irradiation should be considered as a first-line treatment option after first tumor recurrence despite patient age.

\section{Conclusion}

Mesenchymal chondrosarcoma remains a significant management challenge with a poor prognosis due to its rarity and aggressive nature. Surgical resection should be the cornerstone for treating this disease, followed by adjuvant treatment modalities such as radiotherapy and chemotherapy. To our knowledge, it is the first publication presenting hypofractionated stereotactic radiosurgery with Gamma knife, after extraskeletal mesenchymal chondrosarcoma neurosurgical resection. Hypofractionated radiosurgery with a Gamma knife can achieve good local control. However, conventional craniospinal irradiation should be considered the first-line treatment option after the first tumor recurrence due to high metastatic potential.

\section{References}

1. Raza SM, Gidley PW, Meis JM, Grosshans DR, Bell D, et al. (2017) Multimodality treatment of skull base chondrosarcomas: the role of histology specific treatment protocols. Neurosurgery 81(3): 520-530.
2. Bloch OG, Jian BJ, Yang I, Han SJ, Aranda D, et al. (2009) A systematic review of intracranial chondrosarcoma and survival. J Clin Neurosci 16(12): 1547-1551.

3. Dahlin DC, Henderson ED (1962) Mesenchymal chondrosarcoma Further observations on a new entity. Cancer 15: 410-417.

4. Inenaga C, Morii K, Tamura T, Tanaka R, Takahashi H (2003) Mesenchymal chondrosarcoma of the sellar region. Acta Neurochirurgica (Wien) 145(7): 593-597.

5. N Sadashiva, A Sharma, D Shukla, P Rajalakshmi, A Mahadevan, et al. (2016) Intracranial extraskeletal mesenchymal chondrosarcoma. World Neurosurg 95: 618.e1-618.e6.

6. M Salvati, E Caroli, A Frati, M Piccirilli, A Agrillo, et al. (2005) Central nervous system mesenchymal chondrosarcoma. J Exp Clin Cancer Res 24(2): 317-324.

7. GRI Harsh, CB Wilson (1984) Central nervous system mesenchymal chondrosarcoma: Case Report. J Neurosurg, 61(2): 375-381.

8. GC Steiner, JM Mirra, PG Bullough (1973) Mesenchymal chondrosarcoma. A study of the ultrastructure. Cancer 32(4): 926-939.

9. Frezza AM, Cesari M, Baumhoer D, Biau D, Bielack S, et al. (2015) Mesenchymal chondrosarcoma: Prognostic factors and outcome in 113 patients. A European Musculoskeletal Oncology Society study. Eur J Cancer 51(3): 374-381.

10. RC Heros, AJ Martinez, HS Ahn (1980) Intracranial mesenchymal chondrosarcoma. Surg Neurol 14(4): 311-317.

11.JS Rachel, SG David, G Richard, DD Howard (2011) Mesenchymal chondrosarcoma: clinicopathologic study of 20 cases. Arch Pathol Lab Med 136(1): 61-75.

12. Bhardwaj S, Sharma A, Sharma A (2020) Mesenchymal Chondrosarcoma of the Brain with Metastasis: A Case Report with Literature Review. J Neurosci Rural Pract 11(2): 344-348.

13. Ma X, Meng G, Wang K, Li D, Wang L, et al. (2019) The Differences Between Intracranial Mesenchymal Chondrosarcoma and Conventional Chondrosarcoma in Clinical Features and Outcomes. World Neurosurg 122: e1078- e1082.

14. Cho BK, Chi JG, Wang KC, Chang KH, Choi K S (1993) Intracranial mesenchymal chondrosarcoma: a case report and literature review. Childs Nerv Syst 9(05): 295-299.

15. Wang K, Ma XJ, Guo TX, Wang L, Li D, et al. (2018) Intracranial Mesenchymal Chondrosarcoma: Report of 16 Cases. World Neurosurg 116: e691-e698.

16. Sekhar LN, Pranatartiharan R, Chanda A, Wright DC (2001) Chordomas and chondrosarcomas of the skull base: results and complications of surgical management. Neurosurg Focus 10(3): E2.

17. Samii A, Gerganov V, Herold C, Gharabaghi A, Hayashi N, et al. (2009) Surgical treatment of skull base chondrosarcomas. Neurosurg Rev 32: 67-75.

18. Kan Z, Li H, Zhang J, You C (2012) Intracranial mesenchymal chondrosarcoma: case report and literature review. Br J Neurosurg 26(6): 912-914.

19. Bosma JJ, Kirollos RW, Broome J, Eldridge PR (2001) Primary intradural classic chondrosarcoma: Case report and literature review. Neurosurgery 48(2): 420-423.

20.Xiao A, Z Li, X He, C You (2014) A rare tentorial mesenchymal chondrosarcoma in posterior cranial fossa: case report. Neurol Neurochir Pol 48(4): 287-291.

21. Wakabayashi Y, Kodama T, Yamashita M, Nagatomi H (1998) Intracranial mesenchymal chondrosarcoma arising from the cerebellar tentorium: case report. No Shinkei Geka 26(1): 59-64. 
22. Forander T, Rahn L, Kihlstrom E, Ulfarsson T, Mathiesen (2006) Combination of microsurgery and gamma knife surgery for the treatment of intracranial chondrosarcomas. J Neurosurg, 105 (suppl): 18-25

23. Yassa M, Bahary JP, Bourguoin P, Belair M, Berthelet F, Bouthillier A (2005) Intra-parenchymal mesenchymal chondrosarcoma of the cerebellum: case report and review of the literature. J Neurooncol 74(3): 329-331.

24. Anvari K, Gharib M, Saburi A, Javadinia S (2016) Intracranial Mesenchymal Chondrosarcoma: Case Report and Review of Literature. Galen Medical Journal 5(4): 219-224.

25. Lin L, Varikatt W, Dexter M, Ng T (2012) Diagnostic pitfall in the diagnosis of mesenchymal chondrosarcoma arising in the central nervous system: Intracranial mesenchymal chondrosarcoma. Neuropathology 32(1): 8290.

26. Shabani S, Kaushal M, Kaufman B, Knipstein J, Lawlor MW, et al. (2019) Intracranial extraskeletal mesenchymal chondrosarcoma: case report and review of the literature of reported cases in adults and children. World Neurosurgery 129: 302-310.

ISSN: 2574-1241

DOI: 10.26717/BJSTR.2021.35.005729

Andrius Radziunas. Biomed J Sci \& Tech Res

(C) (P) This work is licensed under Creative

Submission Link: https://biomedres.us/submit-manuscript.php
27. Merimsky O, Lepechoux C, Terrier P, Vanel D, Delord JP, et al. (2000) Primary sarcomas of the central nervous system. Oncology 58(3): 210214.

28. Amichetti M, Amelio D, Cianchetti M, Maurizi Enrici R, Minniti G (2010) A systematic review of proton therapy in the treatment of chondrosarcoma of the skull base. Neurosurg Rev 33(2): 155-165.

29. Murakami Y, Jinguji S, Kishida Y, Ichikawa M, Sato T, et al. (2018) Multiple surgical treatments for repeated recurrence of skull base mesenchymal chondrosarcoma. NMC Case Report Journal 5(4): 99-103.

30. La Spina M, Dollo C, Giangaspero F, Bertolini P, Russo G (2003) Intracranial mesenchymal chondrosarcoma with osteoid formation: report of a pediatric case. Childs Nerv Syst 19(9): 680-682.

31. Nozaki K, Nagata I, Takahashi JA, Hashimoto N (1999) Intracranial mesenchymal chondrosarcoma associated with a left transverse sigmoid dural a-v fistule. Acta Neurochirurgica 141(3): 327-328.

$\begin{array}{ll}\text { BIOMEDICAL } & \text { Assets of Publishing with us } \\ \text { RESEARCHES } & \text { - Global archiving of articles } \\ & \text { - Immediate, unrestricted online access } \\ & \text { - }\end{array}$

